\title{
Commentary
}

\section{Mother of a Problem! Are the Needs of Mothers with Intellectual Disability Being Addressed in the NDIS Era? ${ }^{1}$}

\author{
Nikki Wedgwood \\ The University of Sydney, Australia
}

Susan Collings

The University of Sydney, Australia

Margaret Spencer

The University of Sydney, Australia

\section{Gabrielle Hindmarsh}

The University of New South Wales, Australia

\begin{abstract}
The National Disability Insurance Scheme was introduced to provide rightsbased entitlement support for Australians with disability, replacing the previous welfare-based policy framework. However, there are indications this rightsbased support has not eventuated for mothers with intellectual disability, with growing reports of their reduced access to the parenting support to which they are entitled under the Convention on the Rights of Persons with Disability. Despite the NDIS promise of an equitable disability care system that would seamlessly complement State-funded services, reports from mothers with intellectual disability and their advocates suggest that cost-shifting between the Commonwealth and State Governments has reinforced service silos and opened up service gaps for a group of women who need support from both the disability and family support systems. Moreover, a concerning absence of reliable, transparent data makes it difficult to monitor the wellbeing of families headed by mothers with intellectual disability and also suggests these families are no longer a priority for Australian Governments. In this commentary, we advocate for: i) publicly available data on how the NDIS identifies and addresses the support needs of mothers with intellectual disability; ii) the integration of State and Commonwealth funding mechanisms to enable mothers with intellectual disability to access a parenting supplement linked to their NDIS funding and; iii) the rebuilding of national capacity in evidence-based parenting education and support for mothers with intellectual disability across all Australian service systems.
\end{abstract}

Key words: NDIS, Intellectual Disability, Parenting, Mothers.

Corresponding author: Nikki Wedgwood (nicole.wedgwood@sydney.edu.au) Introduction

\footnotetext{
${ }^{1}$ This work was supported by a National Disability Research Partnership (NDRP) Grant.
} 
The Convention on the Rights of Persons with Disability (CRPD), to which Australia is a signatory, declares "States Parties shall render appropriate assistance to persons with disabilities in the performance of their child-rearing responsibilities" (UN 2006 Article 23.2). This includes people with intellectual disability, in practice, primarily women. This is because heteronormative parenting discourses dictate that mothers are the primary caregivers of their children and wear the blame for any parenting deficits; a universal burden women with intellectual disability share with all mothers in Western cultures (Malacrida 2009).

Contrary to widespread ableist assumptions that women with intellectual disability make incompetent mothers, many can and do parent successfully when they receive timely and appropriately-delivered supports, combined with informal assistance from family, friends and/or allies (Collings, Grace \& Llewellyn 2017; Tarleton \& Turney 2020). We already have compelling evidence compiled over several decades on the most effective and appropriate ways to deliver parenting support to mothers with intellectual disability (e.g. Wade, Llewellyn \& Matthews 2008). In short, we know that parenting support must: i) meaningfully involve mothers in any decision-making, ensuring they feel respected and heard (Tarleton \& Turney 2020); ii) provide timely, multifaceted and integrated supports (IASSID Parenting Special Interest Research Group 2008); iii) be co-designed with families, solution-focused and developmental (Spencer \& Llewellyn 2007) and; iv) involve parenting training adapted to individual learning needs and delivered where parenting occurs, i.e. the family home, using positive reinforcement and behavioural-based approaches that break down complex activities into small, concrete tasks (McConnell et al. 2008; Wade, Mildon \& Matthews 2007).

Sadly, this extensive evidence-based knowledge has rarely informed Australian policy. That is, other than a brief period of policy attention between 2004 and 2012, when the Australian Government funded Healthy Start, a national program to build human services systems capacity by training practitioners in the use of evidence-based practices to address the support needs of parents with intellectual disability (McConnell et al. 2008). For the most part, however, Australian mothers with intellectual disability have not received the support they need to raise their children.

\section{Pre-NDIS Supports or Lack Thereof}

Prior to the NDIS, when disability services were funded by the States, many mothers with intellectual disability were deemed 'too high-functioning' to be eligible for the disability-specific parenting support they required. Though eligible for standard parenting programs via family support services, their parenting needs were not adequately addressed by these programs. To be eligible for more intensive parenting support through State-funded family support servicessuch as Brighter Futures in NSW-mothers with intellectual disability would need to accede to having their child/ren being reported as 'at risk of significant harm' to child protection services.

Coming to the attention of child protection is a mother with intellectual disability's biggest fear (Aunos et al. 2020). Because statutory child protection services focus on parenting deficits and child safety risks, the supports provided are involuntary, often 'too little, too late' and the antithesis of what we know works for mothers with intellectual disability and their children (Tarleton \& Turney 2020). Once known to child protection services, mothers with intellectual disability are likely to find their parenting adjudicated in care proceedings because child welfare practitioners are often pessimistic about the chances of keeping families headed by mothers with intellectual disability together (Lewis, Stenfert-Kroese \& O'Brien 2015; Proctor \& Azar 2012). Australian child protection and court processes have been found to discriminate against parents with intellectual disability (McConnell \& Llewellyn 2000; 2002), putting mothers with intellectual disability at high risk of having their children removed once known to the system (Feldman \& Aunos 2020; Llewellyn \& Hindmarsh 2015). 


\section{Support in the NDIS Era}

The promise which the NDIS rights-based model of support held for mothers with intellectual disability was of no longer having to be seen as 'at risk' in order to get support with parenting. In contrast to previous welfare-based support systems they would, in theory at least, receive parenting support as an entitlement. Disappointingly, there are indications this promise has not been realised, with growing concerns about reduced access to appropriate and timely parenting support for mothers with intellectual disability in the NDIS era.

The NDIS has marketized disability services in Australia based on the neoliberal construct of people with disability as individual consumers (Edwards 2019). Subsequently, personalised support packages fund disability-specific supports targeted only to the needs of 'individuals.' Accordingly, a mother with intellectual disability will have her needs assessed as someone with a disability but any needs she has as a mother will be classified as outside the remit of the 'disability' funding category. In concrete terms, if assessed as requiring support with living skills, the NDIS might fund a support worker to: buy and prepare food for her but not for her child/ren; wash up her dishes but not sterilise her baby's bottles and/or; launder her clothes but not those of her child/ren. Although the National Disability Strategy formally recognises that women with disability require access to support services, including parenting support (Commonwealth of Australia 2011), the perverse separation of the support needs of the woman from the support needs of the mother, means that the NDIS does not fund parenting support.

Furthermore, with the coming of the NDIS, State child protection services have devolved responsibility for anyone living with disability to the NDIS - thereby excluding parents with disability from eligibility for early intervention programs (NSW Department of Communities \& Justice 2019). Thus, despite the NDIS assurance of an equitable disability care system that seamlessly complements state-funded services, it seems that neither the Federally-funded NDIS, nor State child welfare systems provide, or fund, parenting support for mothers with intellectual disability. This is concerning given mothers with intellectual disability who do not receive adequate and appropriate parenting support are at high risk of coming into contact with statutory child protection authorities (Feldman \& Aunos 2020; Llewellyn \& Hindmarsh 2015).

Anecdotal reports from mothers with intellectual disability and their advocates suggest that cost-shifting between the Commonwealth and States has reinforced service silos and exposed service gaps for a group of women who need support from both the disability and family support systems (Dyson, Frawley \& Robinson 2017). This is a false-economy, given compelling evidence that disjointed services and negative professional attitudes toward parenting with intellectual disability propel the children of mothers with intellectual disability into statutory child protection and out-of-home care (Collings et al. 2018; McConnell \& Llewellyn 2000; Slayter \& Jensen 2019). All these issues are compounded by discriminatory attitudes and service access barriers encountered by mothers with disability, which the National Disability Strategy acknowledges as a failing (Commonwealth of Australia 2011).

The absence of reliable and transparent data about parental disability from both the Federal Government-responsible for the NDIS and for collecting and making publicly available data about its citizens-and State Governments, which administer and report on social services, makes it incredibly difficult to monitor the wellbeing of families headed by a mother with intellectual disability. It is also further evidence that these families are no longer a priority for 
Australian Governments.

\section{Possible Ways Forward}

The NDIS is currently the primary mechanism through which the Australian Government meets its obligations to uphold the equal rights of Australians with disabilities. By not providing appropriate supports for mothers with intellectual disability, the Government is not only failing to uphold their rights to parenting assistance, it is setting them up for failure.

We suggest the way forward from here requires the following:

- Integrative support - Currently we have two systems that are not working to best serve mothers with intellectual disability to meet their childrearing responsibilities. There needs to be integrative support between NDIS and child welfare which includes seamless provision of appropriate training and support. A way forward would be for the Commonwealth and State Governments to develop a cost-sharing mechanism which enables mothers with intellectual disability who are NDIS participants to access a parenting supplement linked to their NDIS funding. This would give them 'choice and control' over the support they receive to assist with their child rearing responsibilities. Moreover, it would be rights-based support not conditional on their child/ren being registered as at risk of significant harm.

- Rebuild systems capacity - Use the National Disability Insurance Agency's (NDIA) Information, Linkage and Capacity Building program to rebuild capacity across all of Australia's service systems to develop and deliver consistent, evidence-based and highly-skilled service support to mothers with intellectual disability (similar to Healthy Start). In addition, build the capacity of mothers to source accessible parenting information (e.g. the Bumpy Road) and to lead peer-based parenting support communities and programs.

- Maintain datasets - Currently there is little, if any, publicly available data on how the NDIS identifies and addresses the support needs of Australians with intellectual disability with childrearing responsibilities. Despite recognition that "the impact of a child or parent's disability" (NDIS n.d.) gives rise to a need for disability-specific support, there is no reporting mechanism to record the volume or nature of this support. This needs to be urgently rectified.

- Research, policy, practice - Linking State and Federal administrative datasets, including the NDIS, would offer enormous potential for early identification of families at most risk of 'falling through the gaps.' Making such datasets readily available to researchers would enable timely and evidence-based analyses of the NDIS to further inform policy and practice. The New South Wales Government has invested in the Human Services Data Set which links several administrative datasets such as housing, justice, health, child protection and education. Notably, disability data is not included and this absence urgently needs to be addressed to ensure that people with disability are not left behind in any subsequent policy reforms.

Although the promise of rights-based parenting support for mothers with intellectual disability has not eventuated, we believe the full potential of the NDIS is yet to be realised. 


\section{References}

Aunos, M., Hodes, M., Llewellyn, G., Spencer, M., Pacheco, L., Janeslätt, G., Tarleton, B., Springer, L., \& Höglund, B. (2020). The choice of becoming a parent. In R. Stancliffe, M. Wehmeyer, K. Shogren \& B. Abery, (Eds.), (pp. 257-281). Choice, preference, and disability. London: Springer.

Collings, S., Grace, R., \& Llewellyn, G. (2017). The role of formal support in the lives of children of mothers with intellectual disability. Journal of Applied Research in Intellectual Disability, 30(3), 492-500. https://doi.org/10.1111/jar.12361

Collings, S., Spencer, M., Dew, A., \& Dowse, L. (2018). "She was there if I needed to talk or to try and get my point across": Specialist advocacy for parents with intellectual disability in the Australian child protection system. Australian Journal of Human Rights, 24(2), 162-181. https://doi.org/10.1080/1323238X.2018.1478595

Commonwealth of Australia. (2011). National Disability Strategy [2010-2020]. Canberra: Commonwealth of Australia.

Dyson, S., Frawley, P., \& Robinson, S. (2017). "Whatever it Takes": Access for Women with Disabilities to Domestic and Domestic Violence Services: Final report. Sydney: ANROWS.

Edwards, T. (2019). A disabling ideology: Challenging the neoliberal co-optation of independent living under the NDIS. Journal of Australian Political Economy, 83, 3259. https://search.informit.org/doi/10.3316/agispt.20190822015841

Feldman, M., \& Aunos, M. (2020). Recent trends and future directions in research regarding parents with intellectual and developmental disabilities. Current Developmental Disorders Reports, 7, 173-181. https://dx.doi.org/10.1007\%2Fs40474-020-00204-y

IASSID Special Interest Research Group on Parents and Parenting with Intellectual Disabilities. (2008). Parents labelled with intellectual disability: Position of the IASSID SIRG on parents and parenting with intellectual disabilities. Journal of Applied Research in Intellectual Disabilities, 21(4), 296-307. https://doi.org/10.1111/j.14683148.2008.00435.x

Lewis, C., Stenfert-Kroese, B., \& O'Brien, A. (2015). Child and family social workers' experiences of working with parents with intellectual disabilities. Advances in Mental Health and Intellectual Disabilities, 9(6), 327-337. https://doi.org/10.1108/AMHID-032015-0013

Llewellyn, G., \& Hindmarsh, G. (2015). Parents with intellectual disability in a population context. Current Developmental Disorders Reports, 2, 119-126. https://dx.doi.org/10.1007\%2Fs40474-015-0042-x

Malacrida, C. (2009). Performing motherhood in a disablist world: dilemmas of motherhood, femininity and disability. International Journal of Qualitative Studies in Education, 22(1), 99-117. https://doi.org/10.1080/09518390802581927

McConnell, D., \& Llewellyn, G. (2000). Disability and discrimination in statutory child protection proceedings. Disability and Society, 15(6), 883-895. https://doi.org/10.1080/713662015

McConnell, D., \& Llewellyn, G. (2002). Stereotypes, parents with intellectual disability and child protection. The Journal of Social Welfare \& Family Law, 24(3), 297-317. https://doi.org/10.1080/09649060210161294

McConnell, D., Matthews, J., Llewellyn, G., Mildon, R., \& Hindmarsh, G. (2008). "Healthy Start." A national strategy for children of parents with intellectual disabilities. Journal of Policy and Practice in Intellectual Disabilities, 5(3), 194-202. https://doi.org/10.1111/j.1741-1130.2008.00173.x

National Disability Insurance Scheme. (n.d.). Child Protection and Family Support. Retrieved from https://www.ndis.gov.au/understanding/ndis-and-other-governmentservices/family-support

NSW Department of Communities \& Justice. (2019). Targeted Earlier Intervention. NSW Department of Communities \& Justice 
https://www.facs.nsw.gov.au/providers/children-families/early-intervention/TElprogram

Proctor, S., \& Azar, S. (2012). The effect of parental intellectual disability status on child protection service worker decision-making. Journal of Intellectual Disability Research, 57(12), 1104-1116. https://doi.org/10.1111/j.1365-2788.2012.01623.x

Slayter, E., \& Jensen, J. (2019). Parents with intellectual disabilities in the child protection system. Children and Youth Services Review, 98, 297-230. https://doi.org/10.1016/j.childyouth.2019.01.013

Spencer, M., \& Llewellyn, G. (2007). Working things out together: A collaborative approach to supporting parents with intellectual disability. In C. Bigby, C. Fyffe \& E. Ozanne (Eds.), Planning and support for people with intellectual disabilities: Issues for case managers and other professionals (pp. 171-190). London: Jessica Kingsley Publishers.

Tarleton, B., \& Turney, D. (2020). Understanding 'successful practice/s' with parents with learning difficulties when there are concerns about child neglect: The contribution of social practice theory. Child Indicators Research, 13, 387-409. https://doi.org/10.1007/s12187-019-09682-y

United Nations. (2006). Convention on the Rights of Persons with Disabilities. 13 December 2006, A/RES/61/106, Annex I: https://www.refworld.org/docid/4680cd212.html [accessed 25 June 2021]

Wade, C., Llewellyn, G., \& Matthews, J. (2008). Review of parent training interventions for parents with intellectual disability. Journal of Applied Research in Intellectual Disabilities, 21, 351-366. https://doi.org/10.1111/j.1468-3148.2008.00449.x

Wade, C., Mildon, R., \& Matthews, J. (2007). Service delivery to parents with an intellectual disability: Family-centred or professionally centred? Journal of Applied Research in Intellectual Disabilities, 20(2), 87-98. https://doi.org/10.1111/j.1468$\underline{3148.2005 .00297 . x}$

\section{Biographical Notes}

Nikki Wedgwood, PhD, is a sociologist in the School of Health Sciences at The University of Sydney, where she teaches future health professionals about the social determinants of health and the social model of disability. A sociologist with a passion for social justice, her areas of expertise include disability, gender, embodiment, sport and life story research. Her previous research has included looking at the role of sport in the lives of young people with disabilities and exploring the transitioning to adulthood of young Australians with disability. Current research projects include an examination of the interface between the NDIS and family support services for mothers with intellectual disability in New South Wales and an investigation of a continuum of best practices for the inclusion of students with intellectual disabilities in the Australian higher education sector.

Susan Collings, PhD, is Research Fellow at the Research Centre for Children and Families at the University of Sydney. She is Program Lead, Disability and Child Protection and an affiliate with the Centre for Disability Research and Policy. Her research focuses on understanding and supporting families and communities, particularly in the context of child protection and out-of-home care. She is internationally recognised for her research about parents with intellectual disability and their children and has contributed to policy, practice and research on complex support needs, birth family contact and disability support planning. Dr Collings uses arts-based 
methods that open space for people with lived experience to challenge dominant narratives and empowers them to be leaders in system change. She is currently undertaking inclusive research to inform clinical practice in parenting assessment with parents with intellectual disability.

Margaret Spencer PhD BSW BTh Winston Churchill Fellow (1999) lectures in the Social Work Program in the Faculty of Arts and Social Sciences, University of Sydney. Her doctorate and ongoing research focus is on parenting with intellectual disability. She is a research affiliate with University of Sydney's Research Centre for Children and Families and the Centre for Disability Research and Policy; executive member of the IASSID's Parenting Special Interest Group; and member of the Australasian Society for Intellectual Disability (ASID). Margaret has over 35 years practice experience working with parents with intellectual disability and their children. She was the disability family consultant with FAMS NSW (1995-2003) and coordinator of the Intellectual Disability Rights Services' Parent Access Program (2009-2014) which coordinated a specialist advocacy program for parents with intellectual disability involved in child custody matters in the NSW Children Court.

Gabrielle Hindmarsh, PhD, is a Postdoctoral Research Fellow in the School of Psychiatry at UNSW, and a research affiliate at the Centre for Disability Research and Policy at The University of Sydney. She has research interests in the developmental outcomes and wellbeing of children who experience disadvantage, more specifically children with disabilities or who have parents with disabilities. Her work utilises population data to address the inequities families with child and/or parental disability experience. Currently she is exploring the health and wellbeing of children with disabilities in the NSW Child Development Study which has linked administrative health, education, child protection, and justice data. She is a member of the UNSW research team, commissioned by the NSW Department of Education, the lead agency of the National Disability Data Asset (NDDA) Early Childhood Test Case, which is examining the health, educational and social service use among children identified with disability prior to school entry. 